\title{
Multiphase Flow Models in Packed Beds
}

\author{
R.G. Carbonell \\ 1 Department of Chemical Engineering, North Carolina State University, Raleigh, NC 27695-7905 - USA \\ e-mail: ruben@ncsu.edu
}

\begin{abstract}
Résumé - Modèles d'écoulements polyphasiques dans les lits garnis - Cette étude présente un examen des théories sur les écoulements des liquides et des gaz dans les lits garnis appliquées au dimensionnement des réacteurs. Des progrès significatifs ont été réalisés dans la connaissance des phénomènes d'écoulements polyphasiques dans les lits garnis et dans la possibilité d'effectuer des prévisions quantitatives sur le comportement des fluides en écoulement. Certaines théories utilisent avec succès des équations de continuité et de quantité de mouvement moyennées dans l'espace pour les phases liquide et gazeuse, associées à des lois de comportement représentant les forces de trânée entre les phases fluides et les particules ainsi que les effets de la pression capillaire dans la colonne. Il en résulte un ensemble cohérent d'équations qui sont capables de modéliser les données expérimentales pour le taux de rétention du liquide et la perte de charge dans des conditions de régime permanent. Ces théories ont également été utilisées pour donner des informations sur la stabilité de ces écoulements permanents.

Un accord remarquable a été trouvé entre les observations expérimentales et les prédictions théoriques sur les transitions entre les régimes à faibles et à fortes interactions. De plus, le même ensemble d'équations a permis de modéliser les écoulements, à la fois en co- et en contre-courant, des phases liquide et gazeuse dans les lits garnis. Cette approche robuste est basée sur les principes fondamentaux de la mécanique des fluides et peut être appliquée à d'autres configurations de réacteurs. Une formulation similaire a également amélioré la compréhension de l'hydrodynamique des réacteurs à gazosiphon. Certains de ces résultats sont présentés à titre de comparaison ; un résumé des challenges visant à élargir ces modèles hydrodynamiques pour y inclure les effets du transfert de chaleur, du transfert de masse et des vitesses de réaction est également proposé.
\end{abstract}

Mots-clés : force de traînée, perméabilité, perte de charge, rétention, débits de transition, régime hydrodynamique.

\begin{abstract}
Multiphase Flow Models in Packed Beds_This paper presents a review of theories for gas and liquid flows in packed beds as applied to chemical reactor design. Significant progress has been made in understanding multiphase flow phenomena in packed beds and the ability to make quantitative predictions of flow behavior. Successful theories use spatially averaged continuity and momentum equations for the gas and liquid phases, coupled with constitutive equations for drag forces between the fluid phases and the particles and for capillary pressure effects in the column. The result is a selfconsistent set of equations that are able to model experimental data for liquid holdup and pressure drop under steady-state conditions. These theories have also been used to generate information on the stability of these steady-state flows.

Remarkable agreement has been found between the theoretical predictions of the transitions from the low-interaction to the high-interaction regimes and experimental observations. In addition, the same set of equations has been successful in modeling both cocurrent and countercurrent flows of gas and liquid phases in packed beds. This is a robust approach based on fundamental principles of fluid mechanics
\end{abstract}


that can be applied to other reactor configurations. A similar formulation has also led to improvements in understanding of gas lift reactor hydrodynamics, and some of these results will be presented for comparison. A summary of challenges that exist in extending these hydrodynamic models to include the effects of heat transfer, mass transfer and reaction rates will also be presented.

Keywords: drag force, permeability, pressure drop, holdup, flow transition, hydrodynamic regime.

\section{INTRODUCTION}

Trickle bed reactors with either cocurrent or countercurrent flow of the gas and liquid phases find a wide range of applications in the chemical and petroleum industries (AlDahhan et al., 1997; Gianetto and Specchia, 1992; Biardi and Baldi, 1999). Recently, Attou and Boyer (1999) presented a very complete review of the complex behavior of these reactors. They summarized what is currently known about hydrodynamic flow regimes as a function of gas and liquid flow rates and physical properties, as well as theories and correlations that are available to estimate liquid holdup, pressure drop, and trickling to pulsing flow transitions at both low and high operating pressures. This paper focuses on the various approaches that have been taken to modeling the physics of two-phase flows in packed beds in the last fifteen years, and discusses the current state of knowledge and future challenges in this important area of packed bed reactor design.

\section{TWO-PHASE FLOW MODELS}

Hydrodynamic models should be used to provide insight into the physics of flow transitions, to estimate steady-state reactor parameters such as liquid holdup and pressure drop, and to provide a basis for constructing more complex models that could be used as tools for design and scale-up. Ideally, the hydrodynamic models should allow for nonuniform two- and three-dimensional flows, and should be modifiable to include multi-component reactive species balances, mass transfer rates, wetting characteristics and thermal energy balances. For this reason, models resulting from volume averages of the point equations of motion (continuity and momentum) offer significant advantages over other approaches (Carbonell and Whitaker, 1982; Whitaker, 1969). Sáez (1984) discussed in detail the macroscopic equations of motion governing two-phase flow in packed beds under steady, isothermal non-reaction conditions. The averaging process naturally leads to terms representing the drag forces on the gas and liquid phases. Closure relations for the drag forces need to be derived either from first principles or by semi-empirical approaches to relate them to the flow velocities and volume fractions of each phase, and to the physical properties of the gas, liquid and solid phases. For example, for steady, one-dimensional, incompressible flow of the gas and liquid, the volume- averaged momentum equations take the form (Sáez and Carbonell, 1985):

$$
\varepsilon_{\alpha} \rho_{\alpha} v_{\alpha} \frac{\mathrm{d} v_{\alpha}}{\mathrm{d} z}=-\varepsilon_{\alpha} \frac{\mathrm{d} P_{\alpha}}{\mathrm{d} z}+\varepsilon_{\alpha} \rho_{\alpha} \mathrm{g}-F_{\alpha} \quad(\alpha=l, \mathrm{~g})
$$

The quantity $F_{\alpha}$ is the drag force per unit volume of bed acting on the $\alpha$ phase. In Equation (1), the velocity and pressure are intrinsic volume averages for each phase at a given point in the packed bed, and $\varepsilon_{\alpha}$ is the volume fraction of each phase. The continuity equations for the gas and liquid phases under these conditions reduce to the form:

$$
\begin{aligned}
& L=\varepsilon_{l} \rho_{l} v_{l} \\
& G=\varepsilon_{g} \rho_{g} v_{g}
\end{aligned}
$$

where $L$ and $G$ are the liquid and gas mass fluxes.

Under one-dimensional flow conditions, the liquid holdup and the average flow velocities are essentially independent of position along the bed, so that the inertial term on the lefthand side of Equation (1) is negligible. In this case the pressure gradients in the liquid and gas phases are equal since gradients in liquid saturation are negligible. Since the sum of the volume fractions of the gas and liquid adds up to the bed porosity:

$$
\varepsilon_{g}+\varepsilon_{l}=\varepsilon
$$

knowledge of the total gas and liquid mass fluxes ( $G$ and $L$ ) and of the expressions for the drag forces is sufficient to calculate both the pressure drop in the bed and the volume fraction of the liquid phase. Thus, the coupling between the equations of momentum and continuity of the two phases dictates the relationship between holdup and pressure drop, and it is not necessary to have a separate correlation for each of these hydrodynamic parameters. The key to the entire approach is the determination of the drag forces $F_{l}$ and $F_{g}$. Three distinct approaches have been used to obtain these drag expressions:

- the relative permeability model;

- the slit model;

- the fluid-fluid interfacial force model.

These approaches are discussed below in some detail.

\subsection{The Relative Permeability Model}

Sáez and Carbonell (1985) utilized the concept of a relative permeability $k_{\alpha}$ for each phase (commonly used in the 
analysis of two-phase flows in porous media) to write expressions for the drag force per unit volume of each fluid:

$$
\frac{F_{\alpha}}{\varepsilon_{\alpha}}=\frac{1}{k_{\alpha}\left(S_{\alpha}\right)}\left(A \frac{\operatorname{Re}_{\alpha}}{\mathrm{Ga}_{\alpha}}+B \frac{\operatorname{Re}_{\alpha}^{2}}{\mathrm{Ga}_{\alpha}}\right) \rho_{\alpha} \mathrm{g}
$$

The relative permeabilities of the gas and liquid are normally assumed to be primarily a function of the saturation of each phase:

$$
S_{\alpha}=\frac{\varepsilon_{\alpha}}{\varepsilon}
$$

The quantities $A$ and $B$ in Equation (4) are the Ergun equation coefficients for single-phase flow in the packed bed (Ergun, 1952). The Reynolds and Galileo numbers are calculated using the superficial velocity of each phase $\left(\varepsilon_{\alpha} v_{\alpha}\right)$, the equivalent particle diameter $d_{e}$ for non-spherical particles, and the density and viscosity $\left(\rho_{\alpha}, \mu_{\alpha}\right)$ of each phase:

$$
\begin{aligned}
\operatorname{Re}_{\alpha} & =\frac{\rho_{\alpha} \varepsilon_{\alpha} v_{\alpha} d_{e}}{(1-\varepsilon)} \\
\mathrm{Ga}_{\alpha} & =\frac{\rho_{\alpha}^{2} \mathrm{~g} d_{e}^{3} \varepsilon^{3}}{\mu_{\alpha}^{2}(1-\varepsilon)^{3}} \\
d_{e} & =\frac{6 V_{p}}{A_{p}}
\end{aligned}
$$

As can be seen from the form of Equation (4), the relative permeability is defined as the ratio of the single-phase drag force at a given fluid superficial velocity to the drag force under two-phase flow conditions.

Sáez and Carbonell (1985) analyzed data for liquid holdup and pressure drop available in the literature over a wide range of Reynolds and Galileo numbers in packed beds, to determine the dependence of the relative permeability on the saturation for each phase. They correlated the available information in the form:

$$
\begin{aligned}
& k_{l}=\delta_{l}^{2.43} \\
& k_{g}=\left(S_{g}\right)^{4.80}
\end{aligned}
$$

The quantity $\delta_{l}$ in Equation (7) is the reduced liquid saturation:

$$
\delta_{l}=\frac{S_{l}-S_{l}^{0}}{1-S_{l}^{0}}
$$

Expressing $k_{l}$ in this form suggests that the saturation corresponding to the static liquid holdup $\left(S_{l}^{0}=\varepsilon_{l}^{0} / \varepsilon\right)$ consists of essentially stagnant liquid. The use of a reduced liquid saturation in the formula for the liquid phase relative permeability is common practice in two-phase flow analyses. Information on static liquid holdup in packed beds (Kramer, 1998; Sáez et al., 1986, 1991; Mao et al., 1993) indicates values from 0.04 to 0.1 for the normal range of Eötvös numbers used in practice.

Sáez et al. (1986) analyzed the applicability of the concept of relative permeability to two-phase creeping flow in a constricted tube and in a straight cylindrical tube. They showed that the relative permeability for the liquid and the gas phases are predominantly functions of the saturation of each phase, but with a slight dependence on the gas phase velocity. This has been verified by extensive measurements of liquid and gas relative permeability in packed beds by Levec et al. (1986), and Lakota (1991). For example, Lakota (1991) found that the liquid relative permeability in beds filled with spherical particles was best correlated over two ranges of reduced liquid saturation. For values of $\delta_{l}>0.3$ :

$$
k_{l}=\delta_{l}^{2.92}
$$

while for lower values of the reduced saturation $\left(\delta_{l}<0.3\right)$ :

$$
k_{l}=0.397 \delta_{l}^{2.12}
$$

Lakota (1991) also found that the gas phase relative permeability depended on the gas phase Reynolds number. The correlation for spherical particles took a simple power law form:

$$
k_{g}=\left(S_{g}\right)^{n}
$$

where the exponent $n$ is a function of the gas phase Reynolds number:

$$
n=\chi+0.0478 \operatorname{Re}_{g}^{0.774}
$$

For spheres, the parameter $\chi$ in Equation (12) is 4.368 . In later work, Lakota and Levec (1999) showed that the parameter $\chi$ depends on particle shape as well, but not on particle size. The simpler gas phase relative permeability expressions in Equation (7) do an adequate job of describing the liquid and gas relative permeability over a large range of operating gas phase Reynolds numbers and particles types since it represents an average of data taken with spheres, Raschig rings and cylinders. The results of Levec et al. (1986) and Lakota (1991) demonstrated that relative permeability concepts are valid and extremely useful in correlating two-phase flow data for pressure drop and liquid holdup in a trickle bed.

Once the expressions for the gas and liquid relative permeability are known, the pressure drop in the packed bed can be calculated using Equation (1) for the gas phase, neglecting the inertial term:

$$
\Psi_{g}=\frac{\Delta\left(P_{g}-\rho_{g} \mathrm{~g} z\right)}{\rho_{g} \mathrm{~g} L}=\frac{1}{k_{g}\left(S_{g}\right)}\left(A \frac{\mathrm{Re}_{g}}{\mathrm{Ga}_{g}}+B \frac{\mathrm{Re}_{g}^{2}}{\mathrm{Ga}_{g}}\right)
$$

Equation (13) requires knowledge of the liquid holdup to evaluate $S_{g}$. By equating the pressure drop in the gas phase to 
the pressure drop in the liquid phase, it is possible to obtain an expression for the liquid holdup:

$$
\Psi_{l}=1+\frac{\rho_{g}}{\rho_{l}}\left(\Psi_{g}-1\right)
$$

In the equation above $\psi_{l}$ is the corresponding dimensionless liquid phase piezometric pressure drop defined in Equation (13) for the gas phase. Using Equations (13) and (14), Sáez and Carbonell (1985) were able to fit experimental data for pressure drops and liquid holdup to an accuracy of 15 and $13 \%$ respectively, using Ergun coefficients of $A=180$ and $B=1.8$. This data set included gas phase Reynolds numbers as high as 6000, liquid Reynolds numbers as high as 1500 , and Galileo numbers for liquid and gas as high as $1.3 \times 10^{8}$ and $5 \times 10^{5}$ respectively. This was the first time that the momentum and continuity equations for the gas and liquid phases were used to couple directly the pressure drop and holdup data for two-phase flow in packed beds. Prior to this analysis, the predominant effort had been to obtain independent empirical correlations for liquid holdup and pressure drop.

Even though the relative permeability approach is semiempirical and requires evaluation of the Ergun coefficients, it can certainly lead to good correlations of two-phase flow liquid holdup and pressure drops. Anderson and Sapre (1991) utilized this model to compute flow mal-distributions in trickle bed reactors that agreed very well with experimental observations. This theory has also been used to compute twodimensional temperature distributions in non-uniform flows in trickle bed reactors found in industrial applications (Sapre and Katzer, 1995). It is interesting to note that relative permeability functions deduced from one-dimensional flows can be used satisfactorily to predict more complex twodimensional flows. This is additional evidence that the relative permeability approach is a valid technique for modeling two-phase flows in packed beds. As will be discussed later in this article, the drag force expressions originally developed by Sáez and Carbonell (1985) have also been used to make reasonable predictions of trickling to pulsing flow transitions, and to model two-phase countercurrent flows in packed beds.

\subsection{The Slit Model}

Instead of beginning with the averaged equations of motion for the gas and liquid phases, Holub et al. (1992, 1993) modeled the local flow of liquid and gas around the particles in a trickle bed reactor by the much simpler flow inside a rectangular slit. The width of the slit was related to the void fraction of the porous medium, the liquid was assumed to flow equally on the upper and lower surfaces, and the angle of the slit relative to gravity was related to a tortuosity factor for the packed bed. The surface area per unit volume of solid in this idealized geometry was made equal to the surface area per volume of solid in the real reactor, and the thickness of the liquid film flowing in the slit could be related to the total liquid holdup. The flow in both the gas and liquid phases was taken to be fully developed turbulent flow. Only the laminar region of the universal velocity distribution was taken to be relevant in this flow geometry, and the friction factor at the solid-liquid interface was taken to be equal to the friction factor at the gas-liquid interface.

Even though this is a very simple flow, the model does satisfy local momentum and mass balances for the liquid and gas. As a result, it leads to a similar coupling between liquid holdup and pressure drop as was found in the relative permeability model. Of course, average gas and liquid velocities and pressures within the slit can be related to average interstitial velocities and pressures in the packed bed. In the process of deriving the local flow field in the slit, Holub et al. (1992, 1993) introduced the concept of slip of the velocity and stress fields at the gas-liquid interface:

$$
\begin{aligned}
& v_{i, g}=f_{v} v_{i, l} \\
& \tau_{i, g}=f_{s} \tau_{i, l}
\end{aligned}
$$

If the slip parameters for the velocity and stress $\left(f_{v}, f_{s}\right)$ are anything but 1 , there is a discontinuity in the velocity of the gas and liquid at the interface and a corresponding (but not necessarily related) discontinuity in the shear stress. From a fundamental hydrodynamic point of view it is not reasonable for these discontinuities to exist under conditions of trickle bed reactor operation. The no-slip condition is known to be violated under low-pressure (Knudsen) flow, or for flow of highly viscoelastic polymers that are able to slip along the walls of a conduit; however, the no-slip condition is normally assumed to be valid in continuum flows. Nevertheless, in the Holub et al. (1992, 1993) analysis, Equation (15) provided two adjustable constants that could be used to fit experimental data. Had these slip factors not been introduced (had they been made equal to 1), the analysis of Holub et al. $(1992,1993)$ would have had no adjustable parameters.

In the first attempt to use this model to correlate experimental data Holub et al. (1993) made both slip parameters equal to 0 . In this case, the results of their analysis were identical in form to Equations (13) and (14), but with relative permeability functions for the gas and liquid phases with a cubic dependence on saturation:

$$
\begin{aligned}
& k_{l}=\left(S_{l}\right)^{3} \\
& k_{g}=\left(S_{g}\right)^{3}
\end{aligned}
$$

The relative permeability functions in Equation (16) should be compared to the empirically determined results in Equation (7). Holub et al. (1992, 1993) were successful in fitting holdup and pressure drop data in the literature when the Ergun constants were allowed to be identical to the values measured experimentally in each case. 
Al-Dahhan and Dudukovic (1994) found that data in the high-interaction and high-pressure regimes could not be fit well using Equations (13), (14) and (16). Later, Al-Dahhan et al. (1998) allowed the slip factors in Equation (15) to be functions of the gas and liquid Reynolds numbers and obtained the following relations to fit high-pressure liquid holdup and pressure drop data to the slit model:

$$
\begin{aligned}
& f_{s}=-4.4 \times 10^{-2} \operatorname{Re}_{g}^{0.15} \operatorname{Re}_{l}^{0.15} \\
& f_{v}=-2.3 \operatorname{Re}_{g}^{0.05} \operatorname{Re}_{l}^{-0.05}
\end{aligned}
$$

Both slip factors in Equation (17) are negative. As a result, Equation (15) implies that at the interface the gas is moving in the direction opposite to the liquid, and the stress on the gas is the negative of the stress on the liquid. Since this situation is physically unrealistic, the details of two-phase flow around particles in a real packed bed cannot be inferred from the flows predicted by the slit model.

Recently, Iliuta and Larachi (1999) developed a generalized slit model which allows for a distribution of slits that are totally dry in addition to slits that have liquid flow along the walls as in the Holub et al. $(1992,1993)$ and Al-Dahhan et al. (1998) models. In principle, this allows for situations in which the particles are only partially covered by liquid. Iliuta and Larachi (1999) used the same slip factors in Equation (17) for their calculations, but had an additional parameter for the distribution between liquid-full and dry slits. Table 1 shows the results of the generalized slit model compared to those of the relative permeability model (Sáez and Carbonell, 1985), the slit model with the slip factor correlations in Equation (17) and experimental correlations by Ellman et al. (1988, 1990) and Larachi et al. (1991a). Significant portions of the data used for comparison with these models are in the high-pressure and high-interaction regimes.

\section{TABLE 1}

Mean absolute relative errors (\%) calculated by Iliuta and Larachi (1999) for holdup and pressure drop using the generalized slit model compared to other correlations

\begin{tabular}{l|c|c}
\hline Correlations & Liquid holdup $\varepsilon_{\boldsymbol{l}}$ & Pressure drop $\Delta \boldsymbol{P}_{\boldsymbol{g}} / \boldsymbol{L}$ \\
\hline Iliuta and Larachi (1999) & 18 & 27 \\
Sáez and Carbonell (1985) & 22 & 41 \\
Al-Dahhan et al. (1998) & 17 & 32 \\
Ellman et al. (1988, 1990) & 23 & 54 \\
Larachi et al. (1991a) & 23 & 73 \\
\hline
\end{tabular}

Table 1 shows that there is not much difference between the older correlations based on relative permeability theory and the most recent slit model. The reason for this is that two-phase flow pressure drop and holdup measurements are subject to significant experimental variations from laboratory to laboratory and indeed, from packing to packing. It is difficult to pack the same bed with a wide variety of packing materials and liquids with different viscosities and surface tensions and obtain much less than 15 to $20 \%$ variations from experiment to experiment. The available correlations seem to fit the data almost to the limit of this variation.

\subsection{The Fluid-Fluid Interfacial Force Model}

In an effort to avoid the empiricism of the relative permeability and slit models, Attou and Boyer (1999) developed a model in which the drag force on each phase has contributions from the particle-fluid interactions as well as from fluid-fluid interactions. The model was derived from a momentum balance on the fluid flow around fully wetted particles. The particle-liquid and particle-solid interactions have the following general form:

$$
\left.F_{\alpha s}=A_{\alpha s} \overline{v_{\alpha}}+B_{\alpha s} \overline{\left(v_{a}\right.}\right)^{2}
$$

Here the coefficients $A_{\alpha s}$ and $B_{\alpha s}$ are modifications of the Ergun coefficients for single-phase flow in packed beds that account for the distribution of gas and liquid in the pore space available for flow $(\alpha=l, g)$. The quantities $\overline{v_{\alpha}}$ are the superficial velocities for gas and liquid flow in the packed bed. The fluid-fluid drag force expression takes the form:

$$
F_{l g}=A_{l g} \overline{v_{r}}+B_{l g}\left(\overline{v_{r}}\right)^{2}
$$

with the relative velocity between the gas and liquid phases defined by:

$$
\overline{v_{r}}=\overline{v_{g}}-\left(\frac{S_{g}}{S_{l}}\right) \overline{v_{l}}
$$

Attou and Boyer (1999) provided expressions for all the coefficients in Equations (18) and (19). They have shown reasonable agreement with the two-phase flow correlations of Ellman et al. (1988, 1990), Larachi et al. (1991a, 1991b), Holub et al. (1992, 1993) and Wammes et al. (1991a, 1991b). These results are shown in Table 2. This model is remarkable for having no adjustable parameters, and it provides a very good fit of holdup and pressure drop information.

TABLE 2

Mean absolute relative errors (\%) calculated by Attou et al. (1999) for holdup and pressure drop using the fluid-fluid interfacial force model compared to other correlations

\begin{tabular}{l|c|c}
\hline Correlations & $\begin{array}{c}\text { Liquid } \\
\text { holdup } \varepsilon_{\boldsymbol{l}}\end{array}$ & $\begin{array}{c}\text { Pressure } \\
\text { drop } \Delta \boldsymbol{P}_{\boldsymbol{g}} / \boldsymbol{L}\end{array}$ \\
\hline Attou et al. (1999) & 12 & 28 \\
Holub et al. $(1992,1993)$ & 13 & 53 \\
Wammes et al. $(1991 \mathrm{a}, 1991 \mathrm{~b})$, & & 52 \\
Wammes and Westerterp (1991) & 23 & 65 \\
Ellman et al. $(1988,1990)$ & 33 & 77 \\
Larachi et al. $(1991 \mathrm{a}, 1991 \mathrm{~b})$ & 27 & \\
\hline
\end{tabular}


Larachi et al. (1999a) have compared the relative permeability model, the slit model in its various modifications, the fluid-fluid interfacial force model and empirical correlations for liquid holdup and pressure drop to experimental data in the trickling regime. Some of the results from their work are shown in Table 3. These results again indicate that all of these models fit available data to about the same degree of accuracy. However, only the models that are based on the fundamental equations for fluid flow offer the potential for modification to include more complex behavior associated with chemical reactions, mass transfer, phase change and energy transfer across fluid phases.

\section{TABLE 3}

Mean absolute relative errors (\%) calculated by Larachi et al. (1999a) for holdup and pressure drop using various hydrodynamic models and correlations (trickle flow, all data)

\begin{tabular}{l|c|c}
\hline Correlations & Liquid holdup $\varepsilon_{l}$ & Pressure drop $\Delta \boldsymbol{P}_{g} / \boldsymbol{L}$ \\
\hline Sáez and Carbonell (1985) & 19 & 53 \\
Al-Dahhan et al. (1998) & 13 & 68 \\
Holub et al. (1992, 1993) & & \\
(Ergun constants: $A=180$, & & \\
B=1.8) & 18 & 70 \\
Attou et al. (1999) & 20 & 61 \\
(two-equation model) & 25 & 70 \\
Ellman et al. (1988, 1990) & 20 & 72 \\
Larachi et al. (1991a) & & \\
\hline
\end{tabular}

\section{THEORIES OF TRICKLING TO PULSING TRANSITION}

Pulsing behavior in laboratory scale trickle bed reactors consists of pulses of high liquid saturation that travel through the bed at a fairly precise frequency and velocity, depending on the gas and liquid flow rates. The prediction of the transition from the trickling to the pulsing regime by increasing fluid flow rates has been approached from a number of different perspectives. Grosser et al. (1988) and Attou and Ferschneider (1999) have used the macroscopic equations of motion for the gas and the liquid in the packed bed to predict when the steady-state flow becomes unstable. In this theory, the pulsing transition is viewed as being caused by a balance between the inertial forces caused by increased gas and liquid flow, and the capillary pressure gradient which results from gradients in the liquid saturation in the packed bed as a result of these higher inertial forces. The capillary pressure (Scheidegger, 1974) is defined as the volume average pressure difference between the gas and the liquid in a porous medium:

$$
P_{c}=<P_{g}>-<P_{l}>
$$

These pressure differences are the result of surface tension forces that depend on the average curvature of the gas-liquid interfaces, as shown by the Young-Laplace equation:

$$
P_{c}=<\sigma\left(\frac{1}{R_{1}}+\frac{1}{R_{2}}\right)>
$$

In turn, the average principal radii of curvature of the interface $\left(R_{1}, R_{2}\right)$ in a porous medium depend on the contact angle at the gas-liquid-solid contact lines, the pore size distribution, and the liquid saturation.

Leverett (1941) developed a correlation for capillary pressures in packed beds of unconsolidated materials, based on data obtained with various sand samples from 80-100 mesh sizes:

$$
P_{c}=\sigma \sqrt{\frac{\varepsilon}{k}} J\left(S_{l}\right)
$$

The quantity $k$ in the equation above is the permeability of the porous medium, which is related to the Ergun coefficient for viscous flow in a packed bed (Grosser et al., 1988):

$$
\sqrt{\frac{\varepsilon}{k}}=\frac{(1-\varepsilon)}{\varepsilon d_{e}} \sqrt{A}
$$

The Leverett function $J\left(S_{l}\right)$ in Equation (23) depends only on liquid saturation, and ranges from a value of infinity at the residual liquid saturation $\left(S_{l}^{0}\right)$ to 0 when the liquid saturation approaches 1 (complete wetting). The Leverett function also exhibits hysteresis between liquid imbibition and drainage experiments, resulting from differences between the advancing and receding contact angles and the improved wetting of small pores as liquid saturates the column. Recently, Kramer (1998) has presented the results of some elegant experiments showing the influence of capillary pressures in columns filled with porous silica particles from 0.5 to $2.5 \mathrm{~mm}$ diameters. He was able to show capillary liquid rises under static conditions in beds with $2.1 \mathrm{~mm}$ particles that were consistent with calculated capillary pressures. These results offer direct evidence that capillary pressure effects can play an important role in beds with particle sizes that are normally used in trickle bed reactors. It is possible that capillary pressure hysteresis is related to the hysteresis observed in the pressure drops and liquid holdups measured during cocurrent and countercurrent flow in packed beds (Kan and Greenfield, 1978; Levec et al., 1986, 1988; Wang et al., 1998). However, Wang et al. (1995) have attributed the pressure drop hysteresis to varying states of liquid and gas flow uniformity in the column, and have used the Sáez and Carbonell (1985) drag force expressions to model this effect.

Grosser et al. (1988) used the relative permeability drag force expressions for two-phase flow (Sáez and Carbonell, 1985) together with the Leverett correlation for the capillary 
pressure term to obtain a reasonable agreement on the effect of gas and liquid flow rates on the trickling to pulsing transition. Dankworth et al. (1990) used the same model to predict how the velocity of the liquid pulses moving through the bed depends on gas phase velocity, and found very reasonable agreement with the experimental observations of these phenomena by Rao and Drinkenberg (1983). In a rather dramatic indication of the robustness of the relative permeability model, Dankworth and Sundaresan (1989) reversed the direction of flow of the gas phase and were able to obtain reasonable agreement with experimental steady-state liquid holdup and pressure drop data for countercurrent gas-liquid flows in packed beds. In addition, they were able to predict the flooding conditions for countercurrent flow columns, and obtained a remarkable agreement with the correlations of Sherwood and Shipley (1938) and of Hutton and Leung (1974).

Tsochatzidis and Karabelas (1994) studied the details of the microscopic and macroscopic flows during the trickling to pulsing flow transitions in a packed bed. Their data on the effect of gas and liquid flow rates on the transition matched very well with the Grosser et al. (1988) model, as well as the predictions of a model developed by $\mathrm{Ng}$ (1986). The $\mathrm{Ng}$ model was based on the balance between inertial and surface tension forces during two-phase flow inside a single pore. $\mathrm{Ng}$ computed the gas velocity at which the pressure due to the inertia of the gas as it accelerates in the pores and the force of gravity on the liquid phase just balanced the surface tension force causing the liquid to adhere to the particle surface. Values of gas velocity above this number were considered to be in the pulsing flow transition. In this model the liquid flow rate determined the value of the liquid holdup, and this way both the liquid and gas flow rates influence the pulsing transition. The work of Tsochatzidis and Karabelas (1994) clearly shows that the $\mathrm{Ng}$ (1986) model and the Grosser et al. (1988) model predict the same magnitude of gas and liquid velocities for this hydrodynamic transition. Both models predict that at low gas flow rates a higher liquid velocity is required for the transition, and conversely, at low liquid flow rates a higher gas velocity is required. This trend is also in agreement with the general hydrodynamic flow map for trickle beds presented by Gianetto et al. (1978).

Attou and Ferschneider (1999) studied the transition from trickling to pulsing flow using the fluid-fluid interfacial drag force expressions (Attou et al., 1999) together with an approximate capillary pressure term which decreased as the liquid saturation to the minus one third power. This capillary force expression was derived by approximating the curvature of the gas-liquid interface during trickling flow around a single particle. Attou and Ferschneider (1999) found that this model also agreed well with the Grosser et al. (1988) model and with experimental data.

This agreement is in marked contrast with the predictions of the trickling to pulsing transition by Holub et al. (1993).
They theorized that this transition was associated with the effect of gas flow on the formation of waves at the surface of the laminar liquid film flowing around the particles. As shown by Attou and Ferschneider (1999) and Attou and Boyer (1999), the Holub et al. (1993) model predicts that as the liquid flow rate increases the gas flow rate required for the trickling to pulsing transition also increases. This effect is shown in Figure 1, where the dependence of the trickling to pulsing transition on liquid and gas superficial velocities are plotted for the $\mathrm{Ng}$ (1986), the Grosser et al. (1988) and the Holub et al. (1993) models. The experimental data in Figure 1 comes from the work of Chou et al. (1977). The wave formation model of Holub et al. (1993) apparently fails to predict the right dependence of the pulsing transition on gas and liquid velocities. Models that depend on a balance between inertial and capillary forces to predict the trickling to pulsing transition exhibit the right trends of these important variables. This is true of the macroscopic models of Grosser et al. (1988) and Attou and Ferschneider (1999) as well as the microscopic model of $\mathrm{Ng}$ (1986). This is remarkable since these models do not agree on the exact dependence of capillary forces on liquid saturation or the form of the drag force expressions. However, they are all based on a balance between inertial and capillary force terms as a means of explaining the trickling to pulsing transition.

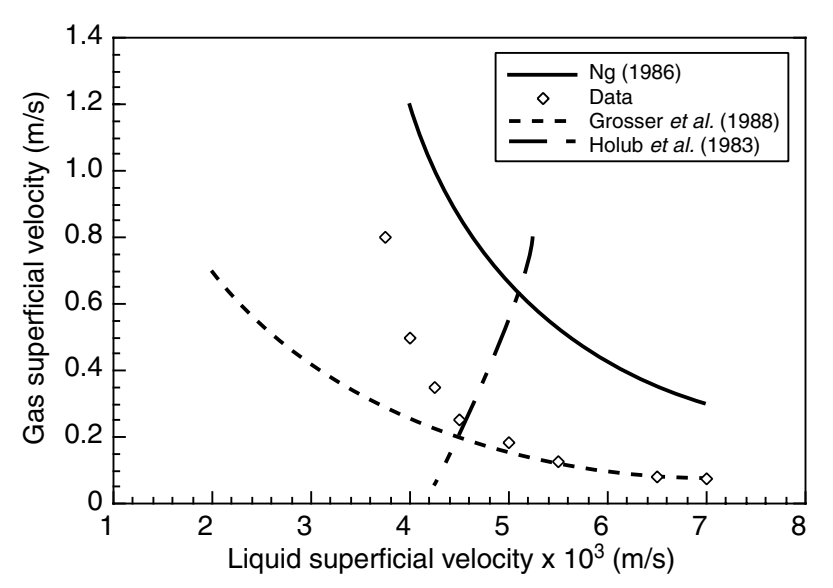

Figure 1

Comparison of the predictions of the Grosser et al. (1988), $\mathrm{Ng}$ (1986) and Holub et al. (1993) models for the trickling to pulsing transition as a function of gas and liquid superficial velocities. The data is from Chou et al. (1977) for a water $+94 \%$ ethanol-air system with glass beads of $2.9 \mathrm{~mm}$ diameter and a bed porosity $\varepsilon=0.39$. The Ergun coefficients for this column were $A=180$ and $B=1.8$. This figure is redrawn from Figure 4 of the review article of Attou and Boyer (1999).

Larachi et al. (1999b) recently presented a much more negative opinion on the status of theories to predict trickling to pulsing transitions. This was based on the large percentage 
error between the model predictions and experimental data. It must be kept in mind that hydrodynamic instabilities in two-phase flow systems are extremely difficult to make quantitative. The same experimental variables that affect the reproducibility in liquid holdup and pressure drop measurements at steady state are present to an even greater extent in measurements of flow stability because of the increased influence of capillary pressure effects. In this context, it is extremely encouraging that the theories that are based on the balance of inertial and capillary forces certainly give the right trends and come close to predicting quantitative values for transition points. It should also be mentioned that Larachi et al. (1999b) list equations for the Grosser et al. (1988) model which are not consistent with the original formulation in several respects, and this might have influenced some of the conclusions drawn in their work.

\section{CONCLUSIONS}

Continuum models based on the equations of motion for the gas and liquid phases offer several advantages for modeling multiphase flow behavior in packed beds. These models can include a correct physical description of the flow processes, and they can be modified to include effects of mass and heat transfer and phase changes at the gas-liquid and liquid-solid interfaces to become useful tools for reactor design. Over the last fifteen years, considerable progress has been made on the development of drag force expressions for two-phase flow in packed beds. In particular, the empirical relative permeability approach of Sáez and Carbonell (1985) and the fluid-fluid interfacial force drag expressions of Attou and Ferschneider (1999) are based on solid hydrodynamic principles and are able to fit available data to within experimental uncertainty. The details of the gas and liquid flows in the slit model with the slip corrections are not realistic and therefore are not a suitable starting point for modification to include reaction, mass transfer and thermal effects.

The balance between fluid inertia and capillary pressure effects seems to be an important factor in the prediction of trickling to pulsing transitions. These transitions do not seem to be dominated by the formation of waves at the gas-liquid interface. The exact form of the capillary pressure-saturation function for the types of particles used in trickle bed reactors is not yet known, but the Leverett function seems to provide a reasonable estimate of the magnitude of the capillary pressure term. For now, this seems to be the only approach that can incorporate capillary pressure effects at low liquid saturation.

Numerous attempts to obtain improved correlations of experimental data for liquid holdup and pressure drop under steady-state conditions are limited by the experimental variations in two-phase flow measurements. Future efforts should concentrate on modifying existing two-phase flow equations of motion to incorporate reaction and heat transfer effects, and on the quantification of physical properties of the gas and liquid phases during high pressure and temperature operations. This should lead to improved models able to provide the practitioner with some important insights into complex interactions between reaction, fluid flow and heat transfer in packed bed reactors.

\section{ACKNOWLEDGEMENT}

The author gratefully acknowledges the support of the William R. Kenan, Jr. Institute for Engineering, Technology and Science at North Carolina State University. The author is also grateful to Dr. Janez Levec and Dr. Ana Lakota of the Department of Chemical Engineering of the University of Ljubljana, Slovenia for information on the results of their liquid and gas relative permeability measurements. The author also wishes to thank Dr. Faiçal Larachi of the Université Laval, Québec, Canada for a preprint of his paper on hydrodynamic models in trickle flow from which Table 3 was constructed.

\section{REFERENCES}

Al-Dahhan, M.H. and Dudukovic, M.P. (1994) Pressure Drop and Liquid Holdup in High Pressure Trickle Bed Reactors. Chem. Eng. Sci., 49, 5681-5698.

Al-Dahhan, M.H., Khadilkar, M.R., Wu, Y. and Dudukovic, M.P. (1998) Prediction of Pressure Drop and Liquid Holdup in HighPressure Trickle-Bed Reactors. Ind. Eng. Chem. Res., 37, 793798.

Al-Dahhan, M.H., Larachi, F., Dudukovic, M.P. and Laurent, A. (1997) High-Pressure Trickle Bed Reactors: A Review. Ind. Eng. Chem. Res., 36, 3292-3314.

Anderson, D.H. and Sapre, A.V. (1991) Trickle Bed Reactor Flow Simulation. AIChE J., 37, 377-382.

Attou, A. and Boyer, C. (1999) Revue des aspects hydrodynamiques des réacteurs catalytiques gaz-liquide-solide à lit fixe arrosé. Oil \& Gas Science and Technology - Revue de l'IFP, 54, 1, 29-66.

Attou, A., Boyer, C. and Ferschneider, G. (1999) Modelling of the Hydrodynamics of the Cocurent Gas-Liquid Trickle Flow through a Trickle-Bed Reactor. Chem. Eng. Sci., 54, 785-802.

Attou, A. and Ferschneider, G. (1999) A Two-Fluid Model for Flow Regime Transition in Gas-Liquid Trickle Bed Reactors. Chem. Eng. Sci., 54, 5031-5037.

Biardi, G. and Baldi, G. (1999) Three-Phase Catalytic Reactors. Catalysis Today, 52, 223-234.

Carbonell, R.G. and Whitaker, S. (1982) Heat and Mass Transport in Porous Media, in Proc. of the Symposium on Mechanics of Fluids in Porous Media, NATO Advanced Study Inst., Univ. of Delaware.

Chou, T.S., Worley, F.L. and Luss, Jr., D. (1977) Transition to Pulsed Flow in Mixed-Phase Cocurrent Downflow through a Packed Bed. Ind. Eng. Chem. Process Des. Dev., 16, 424-427.

Dankworth, D.C. and Sundaresan, S. (1989) A Macroscopic Model for Countercurrent Gas-Liquid Flow in Packed Columns. AIChE J., 35, 1282-1292. 
Dankworth, D.C., Kvrekidis, I.G. and Sundaresan, S. (1990) Dynamics of Pulsing Flow in Trickle Beds. AIChE J., 36, 605621.

Ellman, M.J., Midoux, N., Laurent, A. and Charpentier, J.C. (1988) A New, Improved Pressure Drop Correlation for Trickle Bed Reactors. Chem. Eng. Sci., 43, 2201-2206.

Ellman, M.J., Midoux, N., Wild, G., Laurent, A. and Charpentier, J.C. (1990) A New, Improved Liquid Holdup Correlation for Trickle-Bed Reactors. Chem. Eng. Sci., 45, 1667-1684.

Ergun, S. (1952) Fluid Flow through Packed Columns. Chem. Eng. Prog., 48, 89-94.

Gianetto, A. and Specchia, V. (1992) Trickle Bed Reactors: State of Art and Perspectives. Chem. Eng. Sci., 47, 3197-3213.

Gianetto, A., Baldi, G., Specchia V. and Sicardi, S. (1978) Hydrodynamics and Solid-Liquid Contacting Effectiveness in Trickle-Bed Reactors. AIChE J., 24, 1087-1104.

Grosser, K., Carbonell, R.G. and Sundaresan, S. (1988) Onset of Pulsing in Two-Phase Cocurrent Downflow through a Packed Bed. AIChE J., 34, 1850-1860.

Holub, R.A., Dudukovic, M.P. and Ramachandran, P.A. (1992) A Phenomenological Model for Pressure Drop, Liquid Holdup, and Flow Regime Transition in Gas-Liquid Trickle Flow. Chem. Eng. Sci., 47, 2343-2348.

Holub, R.A., Dudukovic, M.P. and Ramachandran, P.A. (1993) Pressure Drop, Liquid Holdup, and Flow Regime Transition in Trickle Flow. AIChE J., 39, 302-321.

Hutton, B.E.T. and Leung, L.S. (1974) Cocurrent Gas-Liquid Flow in Packed Columns. Chem. Eng. Sci., 29, 1681-1685.

Iliuta, I. and Larachi, F. (1999) The Generalized Slit Model: Pressure Gradient, Liquid Holdup and Wetting Efficiency in GasLiquid Trickle Flow. Chem. Eng. Sci., 54, 5039-5045.

Kan, K.M. and Greenfield, P.F. (1978) Multiple Hydrodynamic States in Cocurrent Two-Phase Down-Flow through Packed Beds. Ind. Eng. Chem. Process. Des. Dev., 17, 482-485.

Kramer, G.J. (1998) Static Liquid Hold-up and Capillary Rise in Packed Beds. Chem. Eng. Sci., 53, 2985-2992.

Lakota, A. (1991) Hydrodynamics and Mass Transfer Characteristics in Trickle Bed Reactor. PhD Thesis, University of Ljubljana, Slovenia.

Lakota, A. and Levec, J. (1999) On the Hydrodynamic Parameter of Trickling Flow in Packed Beds: The Relative Permeability Concept. To be submitted to AIChE J.

Larachi, F., Laurent, A., Midoux, N. and Wild, G. (1991a) Experimental Study of Trickle Bed Reactor Operating at High Pressure: Two-Phase Pressure Drop and Liquid Saturation. Chem. Eng. Sci., 46, 1233-1246.

Larachi, F., Laurent, A., Wild, G. and Midoux, N. (1991b) Some Experimental Liquid Saturation Results in Fixed Bed Reactors Operated at Elevated Pressure in Cocurrent Upflow and Downflow of the Gas and the Liquid. Ind. Eng. Chem. Res., 30, 2404-2410.

Larachi, F., Iliuta, I., Al-Dahhan, M.A. and Dudukovic, M.P. (1999a) Discriminating Trickle-Flow Hydrodynamic Models: Some Recommendations. Ind. Eng. Chem. Res., in press.

Larachi, F., Iliuta, I., Chen, M. and Grandjean, B.P.A. (1999b) Onset of Pulsing in Trickle Beds: Evaluation of Current Tools and State-of-the-Art Correlation. Canadian J. of Chem. Eng., 77, 751-758.

Levec, J., Sáez, A.E. and Carbonell, R.G. (1986) The Hydrodynamics of Trickling Flow in Packed Beds. Part II: Experimental Observations. AIChE J., 32, 369-380.
Levec, J., Grosser, K. and Carbonell, R.G. (1988) The Hysteretic Behavior of Pressure Drop and Liquid Holdup in Trickle Beds. AIChE J., 34, 1027-1030.

Leverett, M.C. (1941) Capillary Behavior in Porous Solids. AIME Trans., 142, 152-169.

Mao, Z.S., Xiong, T.Y. and Chen, J. (1993) Theoretical Prediction of Static Liquid Holdup in Trickle Bed Reactors and Comparison with Experimental Results. Chem. Eng. Sci., 48, 2697-2703.

Ng, K.M. (1986) A Model for Flow Regime Transitions in Cocurrent Down-Flow Trickle-Bed Reactors. AIChE J., 32, 115122.

Rao, V.G. and Drinkenberg, A.H. (1983) Pressure Drop and Hydrodynamic Properties of Pulses in Two Phase Gas Liquid Downflow through Packed Columns. Can. Chem. Eng. J., 62, 158-167.

Sáez, A.E. (1984) Hydrodynamics and Lateral Thermal Dispersion for Gas-Liquid Cocurrent Flow in Packed Beds. PhD Thesis, University of California, Davis.

Sáez, A.E. and Carbonell, R.G. (1985) Hydrodynamic Parameters for Gas-Liquid Cocurrent Flow in Packed Beds. AIChE J., 31, 52-62.

Sáez, A.E., Carbonell, R.G. and Levec, J. (1986) The Hydrodynamics of Trickling Flow in Packed Beds. Part I: Conduit Models. AIChE J., 32, 353-368.

Sáez, A.E., Yépez, M.M., Cabrera, C. and Soria, E.M. (1991) Static Liquid Holdup in Packed Beds of Spherical Particles. AIChE J., 37, 1733-1736.

Sapre, A.V. and Katzer, J.R. (1995) Core of Chemical Reaction Engineering: One Industrial View. AIChE J., 34, 2202-2225.

Scheidegger, A. (1974) The Physics of Flow in Porous Media, 3rd ed., Univ. of Toronto Press, $56 \mathrm{ff}$.

Sherwood, T.K. and Shipley, H. (1938) Flooding Velocities in Packed Columns. Ind. Eng. Chem., 30, 765-769.

Tsochatzidis, N.A. and Karabelas, A.J. (1994) Experiments in Trickle Beds at the Micro- and Macroscale. Flow Characterization and Onset of Pulsing. AIChE J., 33, 1299-1309.

Wammes, W.J.A., Mechielsen, S.J. and Westerterp, K.R. (1991a) The Influence of Pressure on the Liquid Holdup in a Cocurrent Gas-Liquid Trickle-Bed Reactor Operating at Low Gas Velocities. Chem. Eng. Sci., 46, 409-417.

Wammes, W.J.A., Middelkamp, J., Huisman, W.J., deBaas, C.M. and Westerterp, K.R. (1991b) Hydrodynamics in a Cocurrent Gas-Liquid Trickle Bed at High Pressure. AIChE J., 37, 18491862.

Wammes, W.J.A. and Westerterp, K.R. (1991c) Hydrodynamics in a Pressurized Cocurrent Gas-Liquid Trickle Bed Reactor. Chem. Eng. Tech., 14, 406-413.

Wang, R., Mao, Z.S. and Chen, J. (1995) Experimental and Theoretical Studies of Pressure Drop Hysteresis in Trickle Bed Reactors. Chem. Eng. Sci., 50, 2321-2328.

Wang, R., Mao, Z.S., Chen, L. and Chen, J.Y. (1998) Experimental Evidence of Hysteresis of Pressure Drop for Countercurrent Gas-Liquid Flow in a Fixed Bed. Chem. Eng. Sci., 53, 367-369.

Whitaker, S. (1969) Advances in the Theory of Fluid Motion in Porous Media. Ind. Eng. Chem., 61, 12, 14-28.

Final manuscript received in January 2000 